\title{
Pelas brechas do currículo: a forma-ação do processo educativo interétnico em salvador, bahia - 1970-1980
}

\section{Through the gaps in curriculum: the formation/implementation of interethnic educational process in salvador, bahia 1970-980}

DOI: $10.54019 /$ sesv3n1-007

\section{Cristiane Lima Santos Rocha}

Mestre em História Regional e Local - UNEB

Doutoranda em Educação PPED/UNIT

E-mail: mestrado_cristianel@souunit.com.br

\section{Ilka Miglio Mesquita}

Doutora em Educação - UNICAMP

Líder do Grupo de Pesquisa História, Memória, Educação e Identidade

(GPHMEI)

E-mail: ilkamiglio@gmail.com

\section{RESUMO}

O presente texto são considerações iniciais de pesquisa desenvolvida junto ao Programa de Pós-Graduação em Educação da Universidade Tiradentes (UNIT), Aracaju, Brasil, que a partir de uma abordagem qualitativa tem por objetivo examinar o momento de circulação e apropriação política, cultural e institucional da Pedagogia Interétnica nas décadas de 1970 a 1980 em Salvador/Bahia. Através da análise da obra Alternativas para combater o racismo (CRUZ, 1989) e notícias vinculadas nos periódicos Tribuna da Bahia e Diário de Notícias serão tomadas as categorias teóricas de práxis insurgente (WEST, 1999), de insurgência educativa propositiva (WALSH, 2009) e de movimento negro educador (GOMES, 2017) como pilares à compreensão de como a Pedagogia Interétnica se constituiu como manifesto insurgente que propôs divulgar e estabelecer processos educativos de pertencimento étnico que garantissem a valorização das identidades interétnicas.

Palavras-chave: Manifesto Insurgente. Processos educativos. Currículo.

\section{ABSTRACT}

This text are initial considerations of a research developed with The Graduate Program in education of the Tiradentes University (UNIT) in Aracaju, Brazil that, from a qualitative approach, aims to examine the moment of circulation and political, cultural and institutional appropriation of the Interethnic Pedagogy in the 1970 s to 1980 s in Salvador/Bahia. Through the analysis of the work Alternativas para combater o racismo ("Alternatives to combat racism") (CRUZ, 1989) and related news in the periodicals Tribuna da Bahia and Diário de Notícias the theoretical categories of insurgent praxis (WEST, 1999), purposeful educational insurgency (WALSH, 2009) and the black movement as an educational agent 
(GOMES, 2017) will be taken as pillars of understanding how the Interethnic Pedagogy was constituted as an insurgent manifesto that proposed to disseminate and establish educational processes of ethnic belonging that guarantee the valorization of interethnic identities.

Keywords: Insurgent Manifesto. Educational processes. Curriculum.

\section{INTRODUÇÃO}

A epígrafe com que inicio este artigo é da sergipana Maria Beatriz Nascimento historiadora, roteirista, poetisa e militante do movimento negro que deixou importantes contribuições ao buscar estabelecer outras epistemologias que dessem conta das especificidades de mulheres e homens negros na História do Brasil. A referência, dá-se pelo interesse que trago ao exercício de um pensamento crítico que desloca práticas discursivas e percepções de poder; que coloca em questionamento a organização estrutural; que convoca a uma práxis insurgente (WEST, 1999).

Não existo fora do território e das relações que crio. Como já bem enfatizou o geografo baiano Milton Santos "das relações territoriais depende cada vez mais a orientação e eficácia das demais relações sociais" (SANTOS, 2002, p.34). Assim como Beatriz Nascimento(1992), estou sempre em busca de um território, não terra. Território em que as experiências vividas, memórias narradas em primeira pessoa sejam uma verdadeira provocação, permeadas por hesitações e lutas internas.

Não é um exercício fácil, de repente deparo-me numa paciente arqueologia e fina apreciação psicológica de analisar-me enquanto produtora de mensagens que talvez possa provocar a regulação de uma existência coletiva.

A reconstrução das singularidades e subjetividades que permeiam o lugar de onde concebo este texto, faz- me honrar a história, a trajetória, a vivência daquelas e daqueles que se debruçaram em estudar, debater, manifestar as implicações das tecnologias de dominação de pessoas negras, de mulheres.

E foi na busca por território que no início do ano letivo de 2019, através de uma remoção a pedido, fui atuar na Escola Municipal Prof. Manoel de Almeida Cruz, em Cajazeiras XI, bairro periférico de Salvador, no qual também resido. Quis saber quem foi este professor e naquele espaço escolar fui desafiada a entender o lugar específico de produção de memórias, conhecimento, vivência e trajetória 
de luta antirracista deste intelectual negro.

E assim o que ligeira e superficialmente parecia-me ser uma proposta de pesquisa desvinculada da minha trajetória acadêmica nos estudos da história das mulheres e de gênero. Não foi, quando colocado em consideração que o mesmo aparato intelectual baseado em narrativas da ciência positivista que silenciou e silencia as mulheres, silenciam negros, silencia as classes populares deixando-as vulneráveis aos trânsitos e as violências das estruturas coloniais.

A estrutura do patriarcado não está separada das estruturas do racismo, nem do capitalismo. Ao contrário, estão imbricadas a ponto de produzirem estruturas de hierarquização. Deste modo, não apenas gênero como raça e classe podem explicar a deslegitimação, apagamento, ocultamento de conhecimentos de intelectuais negros, deixando-os às margens da produção de epistemes, negando-os enquanto construtores de saberes.

No que me percebi comprometida com a tarefa de reposicionar as epistemes negras apagadas pela colonialidade, em desestabilizar as categorias hegemônicas tanto analíticas, como descritivas que colocam determinados grupos como acêntricos, de forma a manter o apagamento e silenciamento de nossas potências históricas.

Essa prévia, advinda das reflexões incitadas pelo recorte exigido e que culmina nesse texto, é concebido por uma mulher, negra, cada vez mais emersa em escritos de negação da relação unívoca da escola e da visão eurocêntrica, e que trilhando por caminhos desafiantes se volta para a História para memorá-la, para propor espaços de debates centrais ao projeto "Entre o intelectual negro e o manifesto insurgente processos educativos e histórico-educacionais presentes na Pedagogia Interétnica Salvador- Bahia-Nordeste 1970 a 1990"

Que entende o manifesto insurgente denominado Pedagogia Interétnica como uma luta que denuncia os binarismos dicotômicos homem/natureza, mente/corpo, civilizado/bárbaro - e os instrumentos raciais de classificação hierárquica, evidenciando a importância do diálogo entre a experiência negra vivida e o pensamento crítico de forma a transgredir fronteiras discursivas do colonialismo. Diz sobre vida negra e tem protagonista: a trajetória de um intelectual negro Manoel de Almeida Cruz que não é referida em livros, ensaios ou nas chamadas fontes oficiais (HOOKS;WEST, 1991, p.5). 
Mas, através de quais pessoas será possível interpretar a experiência deste intelectual e sua rede de insurgência na produção e proposição do conhecimento nascido na luta ${ }^{1}$ ? Tem sido um dos meus principais questionamentos metodológicos.

"Andar com o Manoel de Almeida Cruz", como sempre sugere minha orientadora Prof ${ }^{-}$Dr $^{\text {a }}$ Ilka Miglio Mesquita que tem me levado a pensar na possibilidade de trilhar com ele, pelo caminho complexo, profícuo, instigante da memória, pois como bem salienta Mesquita (2008) é "recriação da experiência" ainda que "plena de esquecimentos", intencionais e não intencionais, vez que traz as experiências traumáticas que separa, fere corta.

Sem dúvida, poderá vir a ser uma experiência que me dá indícios de que será necessário entrelaçar a ação questionadora, insurgente da Pedagogia Interétnica à prática propositiva (WALSH, 2009), que enegreceu o currículo produzindo um processo educativo politizador, que antecedeu o debate das relações étnico raciais presentes na Lei 10.639/2003, ao encontrar aparato no movimento negro.

Nestas considerações iniciais venho "Pelas brechas do currículo: a forma - ação do processo educativo interétnico - Salvador/Bahia 1970-1980" com preliminares da pesquisa que está sendo desenvolvida na Linha 2: Educação e Formação Docente do Doutorado em Educação do Programa de Pós-Graduação em Educação da Universidade Tiradentes (UNIT) Aracaju, com o objetivo examinar o momento de circulação e apropriação política, cultural e institucional da Pedagogia Interétnica nas décadas de 1970 a 1980. Utilizo o termo brechas para indicar que nas frinchas e gretas das colonialidades "[...] pedagogias insurgentes fraturam a modernidade/colonialidade e tornam possível outras maneiras de ser, estar, pensar, saber, sentir, existir e viver" (WALSH, 2013, p.27), assim como o fez Manoel de Almeida Cruz com a proposta de uma Pedagogia Interétnica.

Para tanto, analiso a obra Alternativas para o combater o racismo: um estudo sobre o preconceito racial e o racismo: uma proposta de intervenção

\footnotetext{
${ }^{1}$ Um tipo específico de conhecimento, a partir de indícios, como sugere formulação de Boaventura de Sousa Santos (2017). SANTOS, Boaventura de Sousa. Prefácio. In: GOMES, NILMA LINO. 0 Movimento Negro Educador. Saberes construídos na luta por emancipação. Petrópolis, RJ: Vozes, 2017.
} 
científica para eliminá-los, escrito e editado por Manoel de Almeida Cruz em 1989, que sistematiza referenciais teóricos da Pedagogia Interétnica, e as notícias vinculadas nos periódicos Tribuna da Bahia e Diário de Notícias. Serão tomadas as categorias teóricas de práxis insurgente (WEST, 1999), de insurgência educativa propositiva (WALSH, 2009) e de movimento negro educador (GOMES, 2017), como pilares à compreensão de como a Pedagogia Interétnica se constituiu como manifesto insurgente que propôs divulgar e estabelecer processos educativos de pertencimento étnico que garantissem a valorização das identidades interétnicas.

\section{DA INSURGÊNCIA PROPOSITIVA}

Nós, entidades negras da Cidade do Salvador e do estado, vimos, através deste, solicitar a V.Exa. a inclusão no Currículo de 1ํgrau do nosso Sistema de Ensino, da disciplina "Introdução aos Estudos Africanos" (CRUZ, 1989, p.81)

O recorte acima é de documento elaborado por entidades negras da Bahia no ano de 1984, apontando dentre os principais pontos de que "a ausência do estudo da história e da cultura Negra, nos currículos escolares, concorria para a falta de identidade cultural e consequentemente, para a inferiorização do povo negro e dos seus descendentes no Brasil", propunham uma reflexão sobre a questão da educação do negro no país e na cidade de Salvador considerando a especificidade de ser território "constituído por um contingente majoritariamente de descendência africana". (CRUZ, 1989, p.81)

Cabe notar que, desde agosto de 1983, o Centro de Estudos AfroOrientais da Universidade Federal da Bahia, em parceria com o Núcleo Cultural Afro-Brasileiro, havia encaminhado um ofício (n.183/1983) solicitando a inclusão da disciplina "Introdução aos Estudos Africanos" nos currículos escolares do $1^{\circ}$ grau. Mas, aquelas vozes insurgentes, vinham de gritos de longe, que devem ser dimensionados a partir do conhecimento nascido na luta na década de 1970, período demarcado pela efervescência cultural e política.

Foi nesse contexto que surgiu o Núcleo Cultural Afro-Brasileiro (1974) apresentando primeira iniciativa de articular as relações raciais à educação, e a construção de uma proposta de difusão no espaço escolar, com propósito de traçar caminhos próprios, enquanto agregador de trajetórias. 
[...] um grupo de onze jovens acaba de criar o Núcleo Cultural Afro-Brasileiro, com sede provisória no Instituto Cultural BrasilAlemanha. A curto prazo, pretende a entidade implantar um curso de Yorubá - língua ainda falada em alguns Terreiros de Candomblé da cidade. A longo prazo, estudos do processo de integração do negro na sociedade brasileira" (Diário de Notícias, 01/08/1974).

Cabe notar como fez Ivan Costa Lima (2004, p.84) para obter reconhecimento público, "o NCAB se estruturou de forma paralela como os departamentos existentes na universidade, tais como: de Sociologia, História, Relações Públicas, Psicologia, Antropologia e Artes.”. Assim, a entidade se estruturou construindo uma proposta pedagógica que teve por principal objetivo debater as relações raciais em Salvador, o que levou a formulação e difusão da Pedagogia Interétnica (1978).

Foi estabelecendo uma rede de insurgências com ações públicas que envolviam seminários, congressos que ampliavam o debate político da questão racial entre os principais grupos do movimento negro, que um dos membros e posteriormente coordenador do Núcleo Cultural Afro-Brasileiro - NUCAB se dedicou a estudos sobre métodos, aspectos estruturais e procedimentos metodológicos que resultaram numa pedagogia própria. Reconhecia, então, o problema colonial sobre os grupos étnicos no Brasil, e buscava apresentar alternativas para combater o racismo no espaço escolar, "sendo uma sistematização, na área da Educação, sobre a realidade pluriétnica e multicultural, tendo como objetivo ser uma resposta cientifica a nível teórico e metodológico na luta contra o racismo. (CRUZ, 1989, p.13)

A problemática do negro brasileiro, como uma raça atingida pelos preconceitos raciais e econômicos, vem sendo estudada e discutida por um grupo pioneiro na Bahia. Formado em sua maioria por negros, o Núcleo Cultural Afro-Brasileiro, com sede provisória, vem, em dois anos de funcionamento, promovendo seminários, debates e cursos, visando "trazer ao negro brasileiro a consciência de sua negritude (Tribuna da Bahia,15/12/1975).

Nacionalmente, caminhava-se para um processo de redemocratização que trazia para o cerne dos debates o reconhecimento de direitos para os desiguais institucionais, o negro, o nordestino e as mulheres, debates que muito 
embora tenham sido investidos do discurso político, não apresentavam respostas efetivas à colonialidade presente na estrutura da sociedade brasileira.

E foi através de uma base teórico-metodológica de desconstrução da situação de opressão dos negros que o NUCAB construiu identidade própria promovendo diversos debates, encontros e simpósios como o I Simpósio sobre o Negro Brasileiro (1975), o II Semana de Estudos e Debates sobre a Problemática do Negro Brasileiro e o I Seminário sobre História Política e Social do Negro no Brasil, em setembro de 1978.

Todas as mobilizações que ocorreram na Bahia na década de 1970 buscavam transformar os resultados decorrentes do debate em práticas efetivas de combate ao racismo nos espaços educacionais com o objetivo principal de:

[...] combater o racismo na Bahia e denunciar os casos ocorridos. Deste encontro resultará um memorial que será encaminhado ao ministro da educação e Cultura, Nei Braga e ao secretário Carlos Santana, sugerindo a introdução, nos currículos escolares, de uma matéria interétnica para conscientizar aos jovens contra a discriminação racial, Roberto Santos disse que este trabalho de reeducação é tudo que o grupo pode propor no momento (Tribuna da Bahia, 25/3/1976).

No que ao longo da década de 1980, os tímidos debates e produções da questão racial fomentadas pela elite intelectual nos meios acadêmicos, permitiram aos intelectuais ligados aos movimentos negro, associarem suas experiências contra o racismo e a discriminação racial, com o debate das relações étnico raciais que ganhavam espaços nas instituições de ensino superior da Bahia.

Em Salvador, o Núcleo Cultural Afro-Brasileiro - NUCAB promovera, em 1980, o II Seminário de Educação Interétnica que resultou na formação de uma comissão encarregada de elaborar um currículo escolar fundamentado na cultura negra. O I Seminário em caráter experimental ocorrera um ano antes também nas dependências do Instituto Cultural Brasil- Alemanha.

Figura 1 - II Seminário de Educação Interétnica 


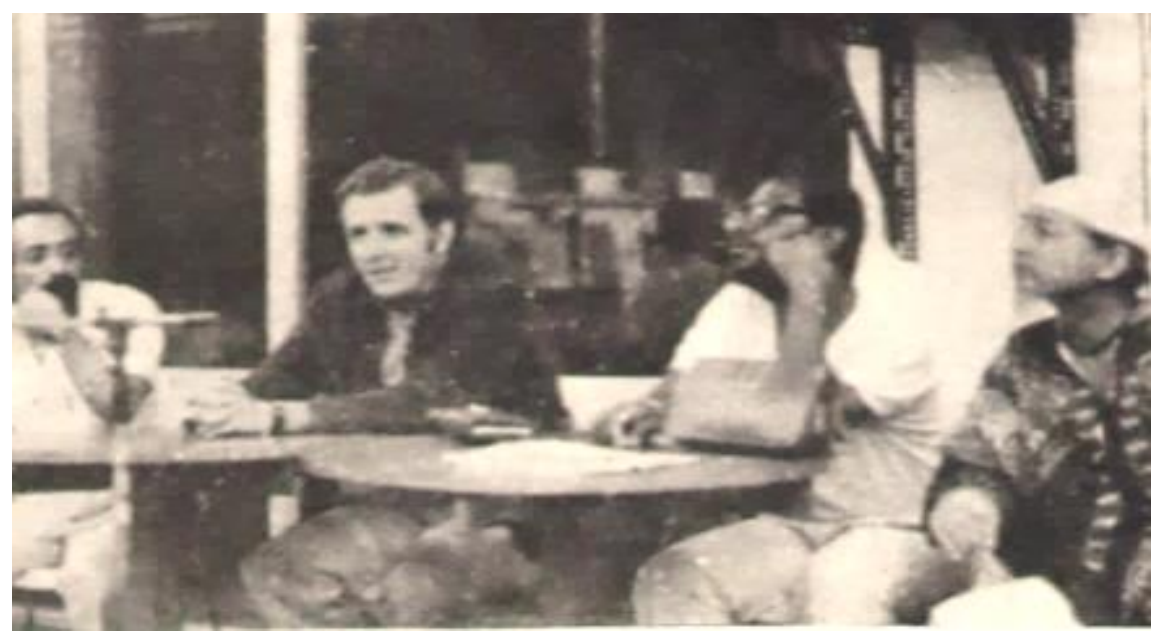

Fonte: Tribuna da Bahia, (04/07/1985). Intelectuais do NUCAB e da UFBA debatem programação do currículo escolar inspirado na Pedagogia Interétnica no Instituto Cultural BrasilAlemanha em 22/09/1980

Primando pela aplicabilidade da música, dança, teatro, modelagem e contos afro-brasileiros, os debates em torno do currículo interétnico seguiriam e nos anos de 1984 a 1985 seriam realizados, em Porto Alegre, respectivamente o I e II Encontro Nacional sobre a Realidade do Negro na Educação propondo nacionalmente "o resgate da cultura e da história do negro no Brasil". (CRUZ, 1989, p.85)

Não são poucas as referências que trazem à tona o papel do Movimento Negro e seu protagonismo na implantação de políticas afirmativas de inclusão de negros nos mais variados setores do Brasil. Não sem razão que Nilma Lino Gomes salienta que:

Movimento Negro é um "produtor de saberes emancipatórios e um sistematizador de conhecimentos sobre a questão racial no Brasil. Saberes transformados em reivindicações, das quais várias se tornaram políticas de Estado nas primeiras décadas do século XXI" (GOMES, 2017, p. 14).

Para Gomes, os movimentos sociais são "os produtores e articuladores dos saberes construídos pelos grupos não hegemônicos e contra hegemônicos da nossa sociedade" (GOMES, 2017, p.16). Dito isto, retomo a 1985, a essa altura, a Pedagogia Interétnica enquanto conjunto de saberes que se colocaram como resistência à dominação epistemológica já se constituía proposta política educacional que objetivava "fornecer instrumentos teóricos e metodológicos, que 
assegurassem um comprometimento com uma filosofia anti-racista, antietnocentrista e progressista [...] à formação de uma consciência emancipadora". (CRUZ, 1989, p.87)

Foi assim que em maio daquele ano, através do Parecer CEE 089/1985, o Conselho Estadual de Educação da Bahia atendeu a reivindicação das entidades negras do estado e aprovou a introdução da disciplina "Introdução dos Estudos Africanos" na parte diversificada da $8^{\mathrm{a}}$ série do $1^{\circ} \mathrm{grau}\left(9^{\circ} \mathrm{ano}\right.$ do ensino fundamental II) das escolas oficiais do estado.

A partir daí estavam colocados dois grandes desafios. Como dar forma à ação? Embora a Pedagogia Interétnica fosse base epistemológica consistente à proposta disciplinar, havia que se pensar numa proposição intercultural, crítica que pluralizasse e problematizasse conhecimentos únicos e universais presentes na Lei de Diretrizes e Bases da Educação 5.692/1971 que organizava os currículos de ensino de $1^{\circ}$ e $2^{\circ}$ graus. Os diferentes tipos de resposta a essa questão, e a muitas outras, remete as vozes de movimentos negros.

Remete ao trabalho de intervenção social e política que intelectuais ligados ao movimento negro estabeleceram, criando formas de autonomia e auto representação. A exemplo da Lélia Gonzalez, crítica do sistema educacional brasileiro, que no cerne trazia a reprodução ideológica de embranquecimento da população negra. Não foram poucas as vezes que Gonzalez denunciava como a organização dos "currículos implementados nas instituições educacionais contribuiu para que afrodescendentes acreditassem na possibilidade de integração social através do esforço pessoal”. (GONZALEZ; HASENBALG,1982, p.19)

Instrumentando a situação para o contexto em análise a proposta interétnica de Manoel de Almeida Cruz em termos étnico raciais estava agregada ao reconhecimento e valorização da população negra, da população indígena na Bahia a partir de mudanças que deveriam ser provocadas nas estruturas da organização educacional, através da própria experiência e do questionamento das ausências a partir das emergências. ${ }^{2}$

Neste sentido, haveria que seguir estabelecendo laços de

\footnotetext{
2 Pensando na formulação teórica da "sociologia das ausências" em consonância a "sociologia das emergências de Boaventura Sousa Santos (2004).
} 
solidariedade para que a forma-ação da proposta tivesse força, de forma a estabelecer redes insurgentes de enfrentamento e combate ao racismo? Para a concreta transformação havia que enveredar nas brechas da complexidade presente no currículo e encontrar maneiras de combater nas estruturas político e sociais o modo de atuação do racismo.

\section{ENEGRECENDO O CURRÍCULO}

Com a aprovação da disciplina "Introdução dos Estudos Africanos" na parte diversificada da $8^{\mathrm{a}}$ série do $1^{\circ} \mathrm{grau}$, "os negros começavam a mostrar suas armas" (Tribuna da Bahia, 04/07/1985), disse Manoel de Almeida Cruz, fazendo referência ao Encontro de negros do Norte/Nordeste, realizado em Salvador entre os dias 6 a 9 de junho de 1985. Nesse encontro foi definido, junto a Secretaria de Educação e Cultura do Estado da Bahia, a aplicação da disciplina em sua primeira etapa, em caráter experimental, nos Colégios Lomanto Júnior e Duque de Caxias logo no ano seguinte, 1986.

Foi assim que, em julho de 1985, a matéria de destaque na página 13 da seção "Variedades" do periódico Tribuna da Bahia, intitulada "Pedagogia Interétnica (Nas escolas a partir de 1986)", de autoria da colunista Angela Peroba, pontuava a Pedagogia Interétnica como matéria sistematizada por ser fruto de pesquisa realizada desde 1978 .

A articulista salienta a importância da proposta de um currículo fundamentado na cultura dos grupos étnicos marginalizados, pois os estudos e formulações presentes na sistematização da Pedagogia Interétnica destacavam como as relações raciais eram permeadas por etnocentrismos, preconceitos que ocasionavam o racismo, sendo este transmitido, principalmente, "pelo processo educacional (família/comunidade/escola)". Dada a palavra ao Manoel de Almeida Cruz, ele destacou na abertura da notícia que:

Não é preciso muita pesquisa para se constatar o racismo entre as relações entre os grupos étnicos. Está na cara, nos pequenos gestos e comportamentos corriqueiros. Nos ônibus, nas escolas, nos playgrounds. Outro dia mesmo o artista Luís Melodia declarava sobre o preconceito racial contra seu filho, quando brincava na área de lazer do edifício. Ou seja, o fato é público e notório. (Tribuna da Bahia, 04/07/1985) 
Nessa argumentação inicial fica perceptível que através da própria experiência negra, Cruz atuava sobre o que lhe permitia entender a realidade à sua volta através de um pensamento crítico que reconhecia o sentido de uma ação política questionadora. É neste sentido, que ele se sentia responsável por transformar os problemas enfrentados pela população indígena e, principalmente, negra nos espaços educacionais, em projetos alternativos que garantissem aos grupos interétnicos condições de desenvolvimento econômico e social.

Em suas próprias palavras havia "comprometimento com uma filosofia educacional libertadora e transformadora da realidade", por isso, tornava público que alimentava o sonho de "vê mudança social com a continuidade da Pedagogia Interétnica enquanto disciplina escolar", pois "o ensino e a discussão desse assunto" implicariam "no grau de consciência e organização dos grupos oprimidos". (Tribuna da Bahia, 04/07/1985)

No que as considerações de Homi K. Bhabha (2003, p.117), de que os intelectuais negros reconhecem no estereótipo, "um modo ambivalente de conhecimento e poder"; e, de Rosemere F. da Silva (2010) ao sugerir que as intervenções teóricas e políticas de intelectuais negros deslocam as imagens construídas em torno da raça de negativas para positivas, na medida que "provocam reflexão desafiadora aos determinismos do discurso colonial". Sendo estas as "armas" necessárias às lutas antirracistas, daí a importância de contextualizar a anterioridade das ações relacionadas a Pedagogia Interétnica.

Falando de sonho, de esperança, Manoel de Almeida Cruz também tocou na ferida: "O Brasil desenvolve no Mito da Democracia Racial [...] uma técnica maquiavélica para a manutenção do preconceito racial, dando a entender lá fora que não existe racismo por aqui”. (Tribuna da Bahia, 04/07/1985)

Dessa forma, Cruz sinalizava o quanto o mito da democracia racial camuflava o racismo de forma a teoricamente ser possível uma convivência harmoniosa, quando na prática os vários estereótipos construídos a partir das características fenotípicas negras, passavam a ser indicadores dos critérios de seleção e de exclusão da população negra do Brasil. Pois como salienta Bhabha (2003) "o estereótipo não é uma simplificação porque é uma falsa representação de uma dada realidade. É uma simplificação porque é uma forma presa, fixa, de 
representação que nega o outro no jogo da diferença (2003, p. 117).

O resultado dessa negação ultrapassa o caráter da formulação teórica do mito da democracia racial, submerge implicações profundas aos grupos étnicos não-brancos, proporcionando às elites a dissimulação das desigualdades e, consequentemente, favorecendo a falta de consciência dos sutis mecanismos de exclusão. (GNACCARINI; QUEIROZ, 1992).

$E$ nesse movimento enquanto "de um lado, setores da universidade, representados pelo CEAO buscava implementar a disciplina" (LIMA, 2004) Introdução dos Estudos Africanos na parte diversificada da $8^{\text {a }}$ série do $1^{\circ}$ grau, paralelamente o NUCAB entendia que na ampliação da adoção da Pedagogia Interétnica nos espaços escolares dar-se-ia o combate à raiz do racismo.

Dois meses depois ao noticiário que divulgou que a Pedagogia Interétnica estaria nas escolas a partir de 1986, foi publicado em mesmo periódico

[...] diretora do CEAO lamentou a falta de recursos para a introdução da disciplina, a partir do próximo ano, nas escolas estaduais. Ela lembrou que a matéria já foi oficializada, através da partida 80/86 de 14 de junho de 85, pela Secretaria de Educação e homologada pelo secretário Edivaldo Boaventura (Tribuna da Bahia, 24/09/1985)

Com bem pontou Ivan Costa Lima (2004, p.98) "ainda que marcadamente não houvesse divergências nas posições explícitas do CEAO e do NUCAB" as redes estabelecidas levaram ao reconhecimento da Pedagogia Interétnica no meio acadêmico. Contudo, no Movimento Negro em Salvador o viés acadêmico da proposta interétnica não foi muito bem absorvido.

Mas, para Manoel de Almeida Cruz na esperança residia tomada de consciência, à "forja da identidade étnica única para o país"(MUNANGA, 2004, p.55) presente nos âmbitos educacionais, especialmente nas "escolas enquanto aparelho ideológico do Estado a transmitir ideologia global da estrutura capitalista, racista, machista e eurocêntrica" (Tribuna da Bahia, 04/07/1985). Haveria de ser otimista que o fenômeno seria revertido a partir de intervenção crítica e produção de conhecimentos fortalecidos no reconhecimento da negritude e dos grupos interétnicos como caminho de construção democrática.

No que promover forma à ação junto a educadoras e educadores da Bahia 
foi "uma ferramenta fundamental para um debate mais consistente sobre as relações raciais e para a concretização de uma outra prática pedagógica preconizada pela Pedagogia Interétnica". (LIMA, 2004, p.120)

Conhecer como foi organizado e aplicado o conhecimento nascido na luta, implica em considerar a memória e a história como importantes dimensões a abordagem das memórias constituintes da identidade (LUCINI, 2007, p. 89) desse intelectual negro, em relação consigo e com sua rede de insurgências que, narradas e renarradas, possibilitará compreender como a Pedagogia Interétnica tornou-se o que é: Manifesto Insurgente.

Mas, trata-se de uma etapa seguinte, por ora cabe dizer que a proposta interétnica, de Manoel de Almeida Cruz, permite também entendê-lo a partir da categoria intelectual insurgente (WEST, 1999), por ter sido um intelectual que articulou discursos, dialogando com as diferenças raciais, apresentando alternativas criativas para circunstâncias precisas que ainda circundam 0 momento presente.

\section{CONSIDERAÇÕES FINAIS}

Em tempos sombrios, como os que vivemos, em que as existências das populações minorizadas encontram-se ainda sob mais forte ameaça, derivada e alimentada por discursos de ódio, discursos de negação da Ciência, discursos que avalizam violência, misoginia, racismo, descaso com as minorias e, consequentemente, a corrosão das instituições democráticas. Cabe a todos e todas, dentro ou fora da academia, dizer do que realmente importa no que se refere à experiência de ser negro, de ser mulher; dizer dos saberes necessários à autoproteção e proteção.

$\mathrm{Na}$ Educação os conflitos sociais e raciais não ficam do lado de fora, por ser construtora de identidades múltiplas e plurais me permite enveredar com inteireza da minha vida de mulher, negra, mãe, educadora no trajeto que nos permitirão construir uma educação antirracista.

E um bom passo para essa construção, é entender que o conhecimento do passado das tradições africanas não é somente conhecer as Áfricas que foram negadas aos afro-brasileiros. É reafirmar a resistência de combate ao racismo a partir de ação conjunta que descortine, denuncie opressão que opera a 
discriminação racial no Brasil.

Essa prévia, advinda das reflexões incitadas pelo recorte exigido buscou compreender as contribuições da Pedagogia Interétnica para uma Educação em prol das noções de pertencimento e identidade de raça, instrumentos indispensáveis às lutas antirracistas, bem como apresentar os desafios pontuais vivenciados para a execução do curriculo interétnico. Atenta à complexidade do contexto que envolvia aquela proposta de combate ao racismo, para tanto, procurei examinar suscintamente o momento de circulação e apropriação política, cultural e institucional da Pedagogia Interétnica nas décadas de 1970 a 1980 em Salvador, Bahia.

Assim, percebo Manoel de Almeida Cruz enquanto intelectual negro antirracista em seus escritos encharcados de sua própria vivência, e as circunstâncias da implementação da Pedagogia Interétnica que permite entendêla como manifesto insurgente com a marca da anterioridade da Lei 10.639/2003. 


\section{REFERÊNCIAS}

BHABHA, Homi. O local da cultura. Trad. Myriam Ávila, et al. Belo Horizonte: Editora UFMG, 2003.

BRASIL. Lei n. 5.692, de 11 de agosto de 1971. Fixa as diretrizes e bases para o ensino de $1^{\circ}$ e $2^{\circ}$ graus, e dá outras providências. Diário Oficial da República Federativa do Brasil, Brasília, 12 de agosto de 1971.

. Lei n. 10.639, de 9 de janeiro de 2003. Inclui no currículo oficial da Rede de Ensino a obrigatoriedade da temática "História e Cultura Afro-Brasileira", e dá outras providências. Diário Oficial da República Federativa do Brasil, Brasília, janeiro de 2003.

CRUZ, Manoel de Almeida. Alternativas para combater o racismo: um estudo sobre o preconceito racial e o racismo. Uma proposta de intervenção científica para eliminá-los. Salvador: Edições Núcleo Cultural Afro Brasileiro, 1989.

GNACCARINI, J. César; QUEIROZ, Renato da Silva. Problèmas ethniques d’un pays multiracial. In: Passarelles, n.5 1992.

GOMES, NILMA LINO. O Movimento Negro Educador. Saberes construídos na luta por emancipação. Petrópolis, RJ: Vozes, 2017.

GONZALEZ, Lélia \& HASENBALG, Carlos. Lugar de Negro. Rio de Janeiro: Editora

Marco Zero, 1982.

HOOKS, Bell. \& WEST, Cornel. Breaking Bread: insurgent black intellectual life. Boston, MA: South End Press, 1991.

LIMA, Ivan Costa. Uma proposta pedagógica do movimento negro no Brasil: pedagogia interétnica de Salvador, uma ação de combate ao racismo. (Dissertação de mestrado). Universidade Federal de Santa Catarina. Florianópolis. SC, 2004.

LUCINI, Marizete. Memória e história na formação da identidade sem terra no assentamento Conquista na Fronteira. Tese (Doutorado) - Universidade Estadual de Campinas: Campinas, SP, 2007.

MESQUITA, Ilka Miglio de. Memórias/ldentidades em relação ao ensino e formação de professores de História: diálogos com fóruns acadêmicos nacionais. Tese (Doutorado) - Universidade Estadual de Campinas: Campinas, SP, 2008.

MUNANGA, Kabengele. Rediscutindo a mestiçagem no Brasil: identidade nacional versus identidade negra. Belo Horizonte: Autêntica, 2004

NASCIMENTO, Maria Beatriz. Por um Território (Novo) Existencial e Físico. In: Texto produzido para a disciplina Teoria da Comunicação, ministrada por Janice Caiafé. 01/08/1992. Cf. Arquivo Nacional. Fundo Maria Beatriz Nascimento. 
Caixas 21. Pasta 3. Dossiê: 4. Código de referência BR NA, RIO 2D.

SANTOS, Boaventura de Sousa. Por uma sociologia das ausências e uma sociologia das emergências. In: SANTOS, Boaventura de Sousa (Org.). Conhecimento prudente para uma vida decente. São Paulo: Cortez, 2004.

SANTOS, Boaventura de Sousa. Prefácio. In: GOMES, Nilma Lino. O Movimento Negro Educador. Saberes construídos na luta por emancipação. Petrópolis, RJ: Vozes, 2017.

SANTOS, Milton. O País Distorcido: o Brasil, a globalização e a cidadania. São Paulo:

Publifolha, 2002.

SILVA, Rosemere Ferreira da. Trajetórias de dois intelectuais negros brasileiros: Abdias Nascimento e Milton Santos. Tese (Doutorado) - Universidade Federal da Bahia: Salvador, BA, 2010

WALSH, Catherine. Interculturalidade crítica e pedagogia decolonial: in-surgir, reexistir e re-viver. In: CANDAU, Vera Maria (Org.). Educação intercultural na América Latina: entre concepções, tensões e propostas. Rio de Janeiro: 7 Letras, 2009 , p. 12-43.

WALSH, Catherine. Introducción. Lo pedagógico y lo decolonial: Entretejiendo caminos. In: WALSH, Catherine. (Org.). Pedagogías decoloniales: Prácticas insurgentes de resistir, (re)existir y (re)vivir. TOMO I. Quito: Abya Yala, 2013, p. 23-68.

WEST, Cornel. The dilemma of the Black Intellectual. In.: AUTOR. The Cornel West: reader. Basic Civitas Books, 1999, p. 302-315. (Tradução e notas de Braulino Pereira de Santana, Guacira Cavalcante e Marcos Aurélio Souza).

\section{FONTES}

\section{LIVRO}

CRUZ, Manoel de Almeida. Alternativas para combater o racismo: um estudo sobre o preconceito racial e o racismo. Uma proposta de intervenção científica para eliminá-los. Salvador: Edições Núcleo Cultural Afro Brasileiro, 1989.

\section{PERIÓDICOS}

Diário de Notícias. Período 1974

Tribuna da Bahia. Período 1975, 1976, 1985 